\title{
Branchial Fistulas-A Rare Entity in Pediatric Otorhinolaryngology: Current Management Protocols and Review of Literature
}

\author{
${ }^{1}$ Ravishankar S Bhat, ${ }^{2}$ Sudhir M Naik, ${ }^{3} \mathrm{MK}$ Goutham, ${ }^{4}$ Shankarnarayan Bhat, ${ }^{5}$ Mohan Appaji, ${ }^{6} \mathrm{KV}$ Chidananda \\ ${ }^{7}$ Nongthomban Pinky Devi, ${ }^{8}$ Sherry Joseph, ${ }^{9}$ Pooja Nayak
}

\begin{abstract}
Background/objectives: Surgical managements which form the mainstay of these branchial apparatus anomalies are based on accurate understanding of the embryology and surgical anatomy. The conspicuous scarring in the young which becomes conspicuous as the age advances are reduced by newer approaches, the facelift approach, retroauricular approach and endoscope-assisted neck approach.
\end{abstract}

Case report: A retrospective case series analysis of eight patients with complete fistula managed by the combined transcervical approach. The recurrence was nil, with good surgical access and minimal scar at the incision site.

Conclusion: Combined transcervical approach is the conventional procedure of choice for branchial fistulas. While retroauricular hairline incision (RAHI) approach and endoscopic approaches need expertise and more instrumentation, meticulous cosmetic surgery techniques helps reduces scars of the transcervical approach.

Keywords: Branchial fistula, Combined approach, Endoscopic approach, Retroauricular hairline.

How to cite this article: Bhat RS, Naik SM, Goutham MK, Bhat S, Appaji M, Chidananda KV, Devi NP, Joseph S, Nayak P. Branchial Fistulas-A Rare Entity in Pediatric Otorhinolaryngology: Current Management Protocols and Review of Literature. Int J Head Neck Surg 2014;5(3):108-111.

Source of support: Nil

Conflict of interest: None

\section{INTRODUCTION}

Surgical managements which form the mainstay of these branchial apparatus anomalies are based on accurate

\footnotetext{
${ }^{1,4}$ Associate Professor, ${ }^{2}$ Fellow, ${ }^{3}$ Assistant Professor ${ }^{5}$ Professor, ${ }^{6}$ Professor and Head, ${ }^{7-9}$ Senior Resident

1,3,5,7-9 Department of ENT, Head and Neck Surgery, KVG Medical College, Sullia, Karnataka, India

${ }^{2}$ Department of Cosmetic and Image Enhancement Surgery Cosmetic Surgery Institute, Mumbai, Maharashtra, India

${ }^{4}$ Department of Anesthesia, KVG Medical College, Sullia Karnataka, India

${ }^{6}$ Department of General Surgery, KVG Medical College, Sullia Karnataka, India
}

Corresponding Author: Ravishankar S Bhat, Associate Professor, Department of ENT, Head and Neck Surgery, KVG Medical College, Sullia, Karnataka, India, Phone: 9916807109 e-mail: drraveesha@gmail.com understanding of the embryology and surgical anatomy. ${ }^{1,2}$ Branchial or pharyngeal arches which appear on the 4th and 5th weeks of development consists of six bars of mesenchymal tissue invaginated by five clefts of ectoderm externally and five pouches of endoderm internally. ${ }^{1,2}$ Second pharyngeal arch proliferates and overgrows $2 \mathrm{nd}, 3 \mathrm{rd}$ and 4 th clefts to fuse with the 5 th arch. ${ }^{1,2}$ The invaginated clefts which form the cervical sinus of his usually disappear, but rarely the remnants may persist as a branchial cyst. ${ }^{1,2}$

Rarely, 2nd branchial arch fails to fuse with the 5th pharyngeal arch forming a branchial sinus which may have an external or internal opening which forms $90 \%$ of the branchial anomalies. ${ }^{3-5}$ Very rarely mesenchymal membrane between the second pharyngeal cleft and pouch break and a complete branchial fistula is formed. ${ }^{1,2}$ A thin membrane is seen at the internal opening even if both ends are patent. ${ }^{6}$

These appear more in males $(60 \%)$ presenting as cysts or fistulas in the second or third decade while congenital sinuses and fistulae appear at birth. ${ }^{78}$ The external opening of sinus lies along the line joining the tragus and the sternoclavicular joint, along the anterior border of sternocleidomastoid with $60 \%$ seen on the left side. ${ }^{9}$ Fistulas of other brachial clefts are very rare and also bilateral branchial fistula are reported. ${ }^{9}$

\section{CASE SERIES}

We report a retrospective case series study of eight patients with branchial fistulas operated in our institution over a study period of 88 months from March 2007 to July 2013. There were eight patients in the group with average of 8.75 years with five males and three females. All had mucous discharge being expressed from the anterior part of the neck through a small fistulous opening (Fig. 1). After examination, a contrast fistulogram was done delineating the fistulous tract (Fig. 2). A contrast computed tomography (CT) with fistulogram was done in two cases which helped intraoperative exploration. All the patients were operated under the combined approach and with probe and methylene blue injected into the fistula to delineate the tract.

The combined approach included an external transverse incision at the fistulous opening trace it above and 


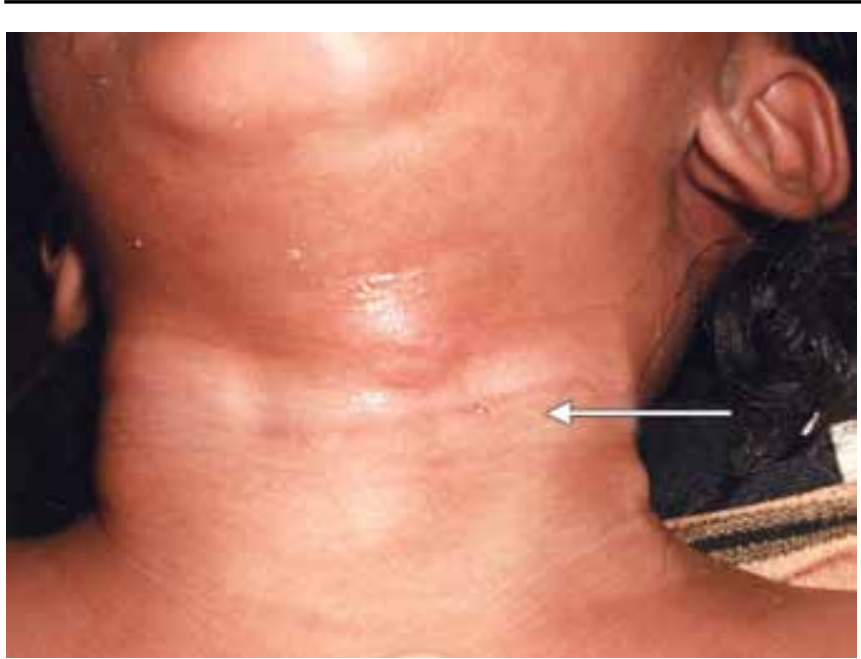

Fig. 1: The external opening of the fistula seen
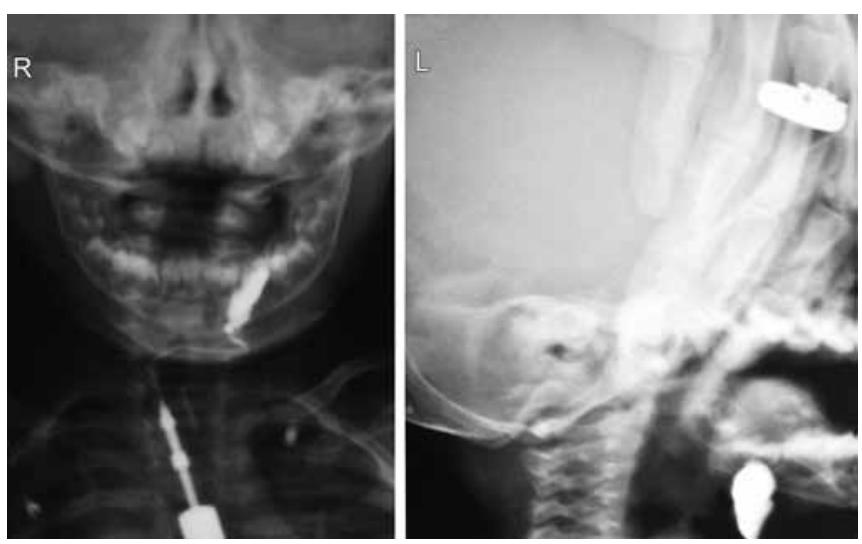

Fig. 2: Contrast fistulogram showing the complete fistula

if not possible to dissect in between the carotids easily then an incision parallel to the mandible $2 \mathrm{~cm}$ below. The dissection is continued and the tract is felt at the tonsillar fossa which will be delivered through the oral cavity if possible. Only one case was delivered orally all the tracts excised from the neck itself, and in two cases, only the upper transverse incision was needed. All cases were palpated intraorally and dissection carried out with tactile feedback. The patients recovered with no scars as the intradermal 5-0 monocryl sutures in 5 and 6 to 0 reverse cutting skin prolene sutures with subcutaneous vicryl were used. No neurovascular damage was seen in any of the cases. No recurrence was seen on follow-up (Table 1).

\section{DISCUSSION}

The fistula passes from the external opening in the mid or lower third of neck in the line of the anterior border of the sternocleidomastoid muscle, deep to platysma along the carotid sheath..$^{10}$ It passes medially deep between the internal and external carotid arteries, after crossing over the glossopharyngeal and hypoglossal nerves and finally opening in the tonsillar fossa..$^{10}$ All of them present with mucoid discharge from the anterior aspect of neck and rarely may get infected forming an abscess with classical redness at the external opening. ${ }^{10}$ The complete fistula is very rare and the internal opening at the tonsillar fossa may rarely be patent, so it is usually a sinus with variable extension into the neck. ${ }^{10}$

Contrast fistulogram is the commonest investigation done which rarely delineates a complete fistula. ${ }^{11}$ Contrast multislice computed tomography fistulogram with $3 \mathrm{D}$ reconstruction delineates the fistula tract from the carotid sheath and the lower cranial nerves. ${ }^{11}$ Imaging helps exact surgical excision which reduces recurrence while reducing morbidity of blind exploration. ${ }^{11}$ Contrast MRI delineates well associated branchial cleft cysts and for parapharyngeal masses that may be second branchial cleft cysts. ${ }^{11}$

Better soft-tissue contrast in T1-weighted images provides better delineation of the upper half of the fistula where it enters the bifurcation and ends opening in the tonsillar fossa. ${ }^{10}$ Ultrasonography using high resolution probes are useful only in cystic lesions which may demonstrate cellular material, cholesterol crystals and keratin..$^{10}$ As management of the fistula is essentially surgical, several approaches are described in literature. ${ }^{10}$ Most commonest is the transcervical approach or a combined pull through technique while other approaches like the retroauricular hairline and endoscopic approach are rarely are also practiced. ${ }^{10}$ The conventional transcervical approach requires a long transverse $5 \mathrm{~cm}$ incision on the neck, for smaller cysts which leaves a scar on the neck. ${ }^{10}$

While complete fistulas need a combined pull through with a larger transverse higher incision in the neck which gives a conspicuous double scar. ${ }^{12}$ The above transverse incision in the combined pull through is bigger compared to the lower incision as the fistula turns deep crossing the important lower cranial nerves and vessels. ${ }^{12}$ The conspicuous scarring in the young which becomes conspicuous as the age advances are reduced by newer approaches, the facelift approach, retroauricular approach, and endoscope-assisted neck approach. ${ }^{12-16}$

Hughes et al and Pingarron et al described the rhytidectomy incision, similar to the Blair's or the modified Blair's incision used for excision of the parotid tumors. ${ }^{13,17}$ The technique allows for a wide surgical approach while difficulties include modified instrumentation and chances of injury to the branches of the facial nerve. ${ }^{13,17}$ There is no donor-site morbidity, minimum additional operating time, hidden scar at the anterior border of the earlobe, no extra cost with good patient satisfaction. ${ }^{13,17}$

Also, the pretragal skin irregularity and the infralobular scar were complained by some patients which led to the retroauricular approach. ${ }^{12-17}$ Its popular as the retroauricular hairline incision (RAHI) approach. ${ }^{12-17}$ The advantage of this incision is that scar is invisible because it is hidden by the auricle and natural hairline. ${ }^{12-17}$ 
Table 1: Overall view of the patients involved in the study

\begin{tabular}{|c|c|c|c|c|c|c|c|c|c|c|c|c|}
\hline \multirow[b]{2}{*}{$\begin{array}{l}\text { Patient } \\
\text { no. }\end{array}$} & \multirow[b]{2}{*}{ Age } & \multirow[b]{2}{*}{ Sex } & \multicolumn{2}{|c|}{ Laterality } & \multicolumn{3}{|c|}{ Symptoms } & \multirow[b]{2}{*}{ Approach } & \multirow{2}{*}{$\begin{array}{l}\text { Post- } \\
\text { operative } \\
\text { follow-up } \\
\text { (months) }\end{array}$} & \multirow[b]{2}{*}{ Technique of skin closure } & \multirow{2}{*}{$\begin{array}{l}\text { Scar } \\
\text { at the } \\
\text { incision } \\
\text { site }\end{array}$} & \multirow[b]{2}{*}{$\begin{array}{l}\text { Recu- } \\
\text { rrence }\end{array}$} \\
\hline & & & Right & Left & $\begin{array}{l}\text { Mucous } \\
\text { discharge }\end{array}$ & Swelling & $\begin{array}{l}\text { Outer } \\
\text { opening } \\
\text { inflamed }\end{array}$ & & & & & \\
\hline 1 & 11 & $\mathrm{M}$ & $\mathrm{R}$ & & Yes & No & Yes & $\begin{array}{l}\text { Combined } \\
\text { external } \\
\text { approach }\end{array}$ & 14 & $\begin{array}{l}\text { Continuous intradermal } \\
5-0 \text { monocryl and } \\
\text { steristrips }\end{array}$ & Minimal & Nil \\
\hline 2 & 9 & $\mathrm{~F}$ & & L & Yes & No & No & $\begin{array}{l}\text { Combined } \\
\text { external } \\
\text { approach }\end{array}$ & 22 & $\begin{array}{l}\text { Simple skin } 6-0 \text { RV } \\
\text { prolene and } 4-0 \text { vicryl } \\
\text { subcutaneous }\end{array}$ & Minimal & Nil \\
\hline 3 & 4 & $\mathrm{~F}$ & $\mathrm{R}$ & & Yes & No & No & $\begin{array}{l}\text { Combined } \\
\text { external } \\
\text { approach }\end{array}$ & 15 & $\begin{array}{l}\text { Continuous intradermal } \\
5-0 \text { monocryl and } \\
\text { steristrips }\end{array}$ & Minimal & Nil \\
\hline 4 & 2 & M & $\mathrm{R}$ & & Yes & No & Yes & $\begin{array}{l}\text { Combined } \\
\text { external } \\
\text { approach }\end{array}$ & 55 & $\begin{array}{l}\text { Continuous intradermal } \\
5-0 \text { monocryl and } \\
\text { steristrips }\end{array}$ & Minimal & Nil \\
\hline 5 & 13 & M & & L & Yes & No & No & $\begin{array}{l}\text { Combined } \\
\text { external } \\
\text { approach }\end{array}$ & 33 & $\begin{array}{l}\text { Continuous intradermal } \\
5-0 \text { monocryl and } \\
\text { steristrips }\end{array}$ & Minimal & Nil \\
\hline 6 & 16 & M & $\mathrm{R}$ & & Yes & No & No & $\begin{array}{l}\text { Combined } \\
\text { external } \\
\text { approach }\end{array}$ & 31 & $\begin{array}{l}\text { Simple skin 6-0 RV } \\
\text { prolene and } 4-0 \text { vicryl } \\
\text { subcutaneous }\end{array}$ & Minimal & Nil \\
\hline 7 & 5 & $\mathrm{M}$ & $\mathrm{R}$ & & Yes & No & No & $\begin{array}{l}\text { Combined } \\
\text { external } \\
\text { approach }\end{array}$ & 48 & $\begin{array}{l}\text { Continuous intradermal } \\
5-0 \text { monocryl and } \\
\text { steristrips }\end{array}$ & Minimal & Nil \\
\hline 8 & 10 & $F$ & & L & Yes & No & Yes & $\begin{array}{l}\text { Combined } \\
\text { external } \\
\text { approach }\end{array}$ & 9 & $\begin{array}{l}\text { Simple skin 6-0 RV } \\
\text { prolene and } 4-0 \text { vicryl } \\
\text { subcutaneous }\end{array}$ & Minimal & Nil \\
\hline
\end{tabular}

The procedure, however, has a narrower surgical field and fiberoptic illumination and flap lift should be optimal to visualize the fistula tract passing in between the vessels and the nerve bundles while releasing the lower opening needs flap elevation into the neck. ${ }^{12-17}$ Also, the smoke or fumes created by use of electrical cautery or the harmonic scalpel needs extra suctioning. ${ }^{12-17}$

Lebert et al reported excellent functional outcomes with the RAHI approach with no marginal mandibular nerve paresis or palsy which are complications with the transcervical approaches. ${ }^{18}$ Temporary earlobe hypoesthesia is seen in some cases. ${ }^{18}$ Flap thinning and buttonholing was minimal with meticulous dissection under illumination and also lesser hypertrophic scars. Operative time increased and the access was narrower. ${ }^{18}$ They found a mean operative time of 110 minutes while in literature it is reported as 45 to 90 minutes with this approach. ${ }^{18}$

The newer endoscopic approach introduced by Guerrissi and Matsui was basically to improve the surgical access and the operative field. ${ }^{16,19}$ Guerrissi also put forth the video-assisted surgery for extirpation of benign tumors as branchiogenic cysts, frontal tumors, frontocygomatic cysts, epidermic nasal cysts, submandibular and sublingual gland diseases. ${ }^{16,19} \mathrm{He}$ also advised the transnasal and transoral approach using endoscopes. 16,19 So, it is noted that new surgical techniques, surgeon experience and advanced endoscopic instruments, the video-assisted endoscopic surgery seems safer while giving optimal disease clearance and cosmetically better option. ${ }^{16,19}$ Guerrissi described the endoscopic approach to be safer and minimally invasive approach, spares unnecessary discomfort to the patient, less prominent operative scars and less compromised surgical field. 16,19

Chen et al showed that endoscope-assisted second branchial cleft cyst resection via retroauricular approach gives a better cosmetic outcome than the conventional transverse cervicotomy incision. ${ }^{20}$ The scars were behind the ears hidden by the auricle and natural hair. ${ }^{20}$ As the cysts were palpable and the fistula subcutaneous, no long shaft endoscopic instruments were needed and the regular longer instruments served the purpose. ${ }^{20}$ Good illumination and high definition magnification of surgical field using a video monitor gives the best access possible. $^{20}$

The course along the carotids its bifurcation and along the lower cranial nerves are accurately visualized and can be dissected efficiently. ${ }^{20}$ The disadvantage of a narrower surgical field and poor access which increases the operative time in facelift approach and the RAHI approach are balanced by the time of setting up the endoscopic instruments. ${ }^{20}$ Only one hand is free in the endoscopic approach so the principles of nasal endoscopic surgery is applied here. ${ }^{20}$ The problems of fogging and suctioning are to be tackled. ${ }^{20}$ 
High resolution and magnification reduced surgical trauma and good hemostasis was present with harmonic scalpel. $^{21}$

The meticulous dissection of the greater auricular nerve prevents the earlobe numbness as it crosses the sternocleidomastoid muscle. ${ }^{20}$ Compromise of the skin flap vascularity at the tips can be reduced by making a thicker flap with no acute angles at the incision. ${ }^{20}$ Also marginal mandibular nerve may be identified at the angle after ligation of the facial veins reducing the paresis. ${ }^{20}$

More studies are to be reported before this endoscopic approach can be taken as a standard approach. 16,19 However, the advantages of smaller scar better visualization with magnification should be equally comparable with minimal great auricular nerve paresis and cyst recurrence. ${ }^{16,19}$ An incidence $9.9 \%$ of metastatic squamous cell carcinoma has been reported in retrospective study of 121 cases. $^{22}$ All these were in the 5 th decade, so a metastatic workup was advised in these cases. ${ }^{22}$

A minimal recurrence rate of $3 \%$ is seen by external approach as difficult dissection at the parapharyngeal space can leave bits of fistula epithelium. But the combined approach leaves no epithelium and recurrence are rare. ${ }^{7}$ Contrast fistulogram using CT or MRI helps tracing the fistula intraoperatively as the priorities of key areas change with different approaches. Using a guidewire helps tracing it till the bifurcation later only tactical meticulous dissection gives better results.

\section{CONCLUSION}

Combined transcervical approach is the conventional procedure of choice for branchial fistulas. While RAHI approach and endoscopic approaches need expertise and more instrumentation, meticulous cosmetic surgery techniques help to reduce scars of the transcervical approach.

\section{REFERENCES}

1. O'Mara W, Amedee RG. Anomalies of the branchial apparatus. J La State Med Soc 1998;150(12):570-573.

2. Sadler TW. Langman's medical embryology. 9th ed. Philadelphia: William and Wilkins 1995;16(1):324-325.

3. Elsurer C, Yilmaz T. First branchial cleft fistula presenting with external opening on earlobe. Eur Arch Otorhinolaryngol 2006;263(2):685-687.
4. Sayadi SJ, Gassab I, Dellai M, Mekki M, Golli M, Elkadhi F. Laser coagulation in the endoscopic management of fourth branchial pouch sinus. Ann Otolaryngol Chir Cervicofac 2006 Jan;123(3):138-142.

5. Ford GR, Balakrishnan A, Evans JN, et al. Branchial cleft and pouch anomalies. J Laryngol Otol 1992 Feb;106(2):137-143.

6. Shekhar C, Kumar R, Mishra SK, Roy M, Bhavana K. The complete branchial fistula: a case report. Ind J Otolaryngol Head Neck Sur 2005 Oct;57(4):320.

7. Ang AH, Pang KP, Tan LK. Complete branchial fistula: case report and review of the literature. Ann Otol Rhinol Laryngol 2001 Nov;110(11):1077-1079.

8. De PR, Mikhail T. A combined approach excision of branchial fistula. J Laryngol Otol 1995;109(3):999-1000.

9. Agaton-Bonilla FC, Gay-Escoda C. Diagnosis and treatment of branchial cleft cysts and fistulae: a retrospective study of 183 patients. Int J Oral Maxillofac Surg 1996 Dec;25(6):449-452.

10. Sahu S, Kumar A, Ramakrishnan TS. Branchial fistula: an imaging perspective. MJAFI 2011;67(3):262-264.

11. Augustine AJ, Pai KR, Govindarajan R. Clinics in diagnostic imaging. Sing Med J 2001 Oct;42(10):494-495.

12. Chen WL, Fang SL. Removal of second branchial cleft cysts using a retroauricular approach. Head Neck 2009 May;31(5): 695-698.

13. Hughes J, Stephens J, Amonoo-Kuofi K, Mochloulis G. Facelift approach to upper cervical surgery. Otolaryngol Head Neck Surg 2009 Dec;141(6):783-785.

14. Roh JL. Retroauricular hairline incision for removal of upper neck masses. Laryngoscope 2005;115(2):2161-2166.

15. Roh JL, Yoon YH. Removal of pediatric branchial cleft cyst using a retroauricular hairline incision (RAHI) approach. Int J Pediatr Otorhinolaryngol 2008;72(3):1503-1507.

16. Guerrissi JO. Minimal invasive surgery in head and neck: videoassisted technique. J Craniofac Surg 2010 May;21(3):882-886.

17. Pingarrón Martin L, Arias Gallo J, González Martín-Moro J, et al. Rhytidectomy approach for surgical treatment of branchial cyst. Oral Maxillofac Surg 2010 Mar;14(1):1-2.

18. LeBert B, Weiss SR, Johnson JT, Walvekar RR. Retroauricular hairline approach for excision of second branchial cleft cysts. Int J Head Neck Surgery 2011 Jan-Apr;2(1):49-52.

19. Matsui $Y$, Iwai T, Tohnai I, Maegawa J. Endoscopically assisted resection of a branchial cyst. Br J Oral Maxillofac Surg 2008 Jun;46(4):336-337.

20. Chen L, Sun W, Wu P, Zhang S, Xu M, Luo X, Zhan J, Huang X. Endoscope-assisted versus conventional second branchial cleft cyst resection. Surg Endosc 2012 May;26(5):1397-1402.

21. Markkanen-Leppänen M, Pitkäranta A. Parotidectomy using the Harmonic scalpel. Laryngoscope 2004 Feb;114(2):381-382.

22. Sun $W, X u$ YD, Zheng YQ, Liu X, Zeng L, Liu W, Huang X. Endoscope-assisted partial-superficial parotidectomy through two small skin incisions. Acta Otolaryngol 2009 Dec;129(12):1493-1497. 